\title{
Preparing for Industry 4.0 - Testing Collaborative Virtual Learning Environments with Students and Professional Trainers
}

\author{
http://dx.doi.org/10.3991/ijac.v8i4.4911 \\ Katharina Schuster, Lana Plumanns, Kerstin Groß, Rene Vossen, Anja Richert and Sabina Jeschke \\ RWTH Aachen University, Aachen, Germany
}

\begin{abstract}
In consideration of future employment domains, engineering students should be prepared to meet the demands of society 4.0 and Industry 4.0 - resulting from a fourth industrial revolution. Based on the technological concept of cyber-physical systems and the Internet of Things, it facilitates - among others - the vision of the smart factory. The vision of "Industry 4.0 " is characterized by highly individualized and at the same time cross-linked production processes. Physical reality and virtuality increasingly melt together and international teams collaborate across the globe within immersive virtual environments. In this context, a large market arises in the field virtual trainings, which means that professional trainers need to explore the potential of new learning settings. In the context of the development from purely document based management systems to complex virtual learning environments (VLEs), a shift towards more interactive and collaborative components within higher educational e-learning can be noticed, but is still far from being called the state of the art. As a result, engineering education is faced with a large potential field of research, which ranges from the technical development and didactical conception of new VLEs to the investigation of students' acceptance or the proof of concept of the VLEs in terms of learning efficiency. This paper presents three corresponding qualitative studies: In a series of focus groups, it was investigated which kinds of VLEs students prefer in a higher education context. Building upon the results of the focus groups, a collaborative VLE was created within the open world game Minecraft. In two different studies this VLE was tested, first by students and then by professional trainers. First screenings of the video material of the studies indicate a connection between communicational behavior and successful collaborative problem solving in virtual environments. The majority of the trainers who participated in the second study ascribe the new technological possibilities great potential and would consider using it within their own trainings.
\end{abstract}

Index Terms-Engineering Education, Professional Training, Virtual Collaboration, Virtual Learning Environments

\section{INTRODUCTION: TODAY'S LEARNING, WORKING} AND TRAINING IN PREPARATION FOR INDUSTRY 4.0

Todays' portfolio of e-learning solutions is as diverse as never before. Different kinds of media services, software for teaching and learning as well as innovative hardware solutions not only become a bigger part in higher education, professional training and the workplace in general but increasingly adapt to the massive changes our working world is going through. A common and frequently cited example is the use of learning management software, based amongst others on the open-source management system Moodle [1]. Today, Moodle counts 53.738 registered installations with 68.7 million users of 226 countries in 7.7 million courses [2]. Platforms like Moodle have different functions, which can also be viewed as elearning solutions themselves: With chats, forums or messenger systems, students or workers can communicate in synchronous or in asynchronous ways. Accomplished tests are rated automatically, which makes the frequent testing also suitable for large groups. Furthermore with the possibility to be tested frequently, the students get instant feedback about their current state of knowledge and their development. Hence, digitally supported learning brings direct individual advantages in terms of self-awareness of the content of the lecture.

The digitalization of education also means that learning becomes more collaborative [3]. The key word "user generated content" describes the fact that in times of web 2.0, content rarely is produced by just one single provider of content, but is generated by several users instead. Transferred to the context of higher education, the students' role changes. Whereas back in the days, when the teacher was more or less the only source who provided information, today students can get basically any information they want from the internet, but can also contribute actively within forums, wikis or blogs. The potential is there to switch the students' role from rather passive users of information to creators of knowledge in networked structures - with all accompanying advantages and disadvantages. With the goal in mind not only to boost the students' knowledge and to support them to strengthen their personality over the years, but also to develop crucial competences for the working world they are about to step in various types of collaboration that have to be trained and tested in learning scenarios. However, not every new approach that is technically feasible improves users' learning outcomes. The danger of designing expensive VLEs without having a positive effect on the development of users' skills and capacities is obvious. Hence, in order to make a valid contribution to the application of virtual learning, especially in terms of collaboration, it is important to consider both, the users or rather students and the trainers perspective.

The difference between cooperative and collaborative learning can thereby be explained as follows: In cooperative learning scenarios, each group member is given a subtask e.g. reading and interpreting different parts of scientific literature, technical reports etc. The individually produced results, e.g. a presentation, are simply being added up. Therefore, the main result mostly doesn't represent the 
state of knowledge of each individual group member. It is more a question of how to divide the work in an efficient, but not necessarily in an effective way.

Collaboration instead focuses on the creation of a new knowledge baseline, which is built through interlinked and co-referenced work during the learning process [4]. Especially in engineering, collaborative learning in virtual environments is highly important in the context of a dynamic and digitalized working world. This can be realized e.g. by analyzing a defective machine, coming up with a logistics concept for a virtual factory or designing a virtual car. The last example points out the importance for engineers to link their own specific technical expertise with expertise of other domains. Working in interdisciplinary teams situated all over the world is standard practice. The increasing digitalization of economy and society links knowledge over borders of time, space and systems. In times of Industry 4.0, physical reality melts with virtuality [5]. For almost decades now, e.g. finite element models, data models, analytical models or CAD-models of machine elements have been produced with software. The data is used, provided and linked within socio-technical working systems via clouds, ubiquitous computing, product-lifecycle management and product data management. Thus, in engineering, human work processes are increasingly being transferred to virtual spaces of an internationally networked world. An outset that have a great potential for trainers and other suppliers, who providing a service that can be offered online and not at least for the users. Lifelong learning gets more important in consideration of future employment but also individual's self- driven willingness to learn and develop increases over the last decades. The possibility to continuing professional development and learning on the job becomes more valued than ever and ranks as one of the principals characteristics of successful universities and (future) organizations [6].

\section{COLLABORATIVE LEARNING IN VIRTUAL ENVIRONMENTS}

In higher engineering education computer-supported cooperative and collaborative learning (CSCL) have long been established as methods which support self-driven and work-related learning processes. By further technical development as well as new requirements of the changing working world such common methods can be lifted to a new level. Virtual learning platforms like moodle can systematically be linked to virtual or teleoperative laboratories. In higher education, every student gets the opportunity to experiment with physically real equipment without the necessity to be physically present at the location of the machine [7]. With special booking systems, expensive equipment for teaching and training processes can be used more efficiently, since students from different time zones (e.g. USA and Germany) can $\log$ in at different schedules. Thus, it is possible to introduce students to learning settings, which would otherwise be too dangerous (e.g. a nuclear power plant), too hard to access (e.g. the surface of Mars) or too big a risk for ongoing production (e.g. in a factory) [8] .

Moreover, in massive open online courses (MOOCs), each student can learn at his or her own speed. Many workers also use this format for their personal further education, e.g. to stay up to date in their field of knowledge or to gain new skills. Serious games offer thepossibilities to learn in a playful manner, in single- player or in multi-player mode. Innovative virtual knowledgespaces therefore offer all kinds of possibilities for learning and working in times of Industry 4.0. But new techologies not only focus on learning and academic development of users, also psychological assistance and trainings are offered within virtual enviroments. An example for today's possibilities is given by TriCAT, an organization that offers virtual enviroments for e.g. online coaching (Figure 1). This way of systemic coaching enables the user getting an individual real-time on-demand coaching from a professional trainer, while saving time and travel costs. The difference from real coaching is solely that trainer and trainee do not interact through their natural body but arise represented through avatars that can be moved freely through different coaching-rooms and are thus able to interact and collaborate like humans in natural environments.

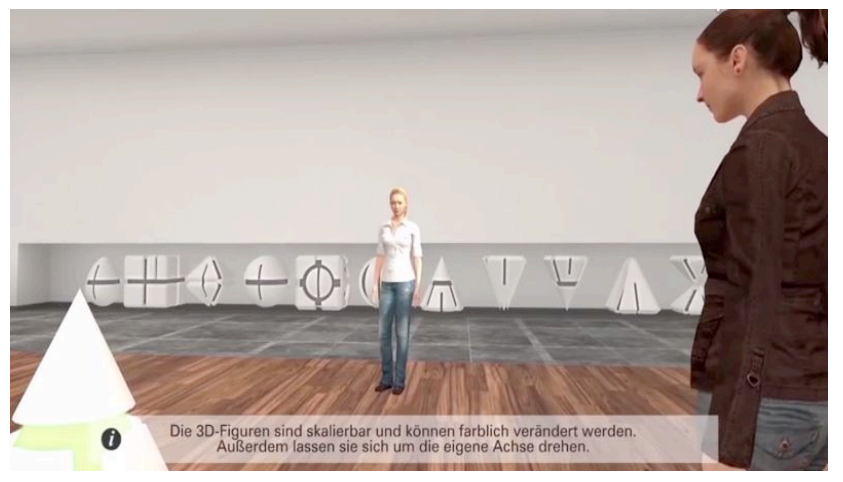

Figure 1. Screenshot of 3D online coaching within the VLE with the aid of avartars

Prensently, the demand for such flexible solutions is of rising interest for universities and working organisations [9]. But still: In order to use the new technologies for learning and education in a proper way, deeper insights in reception, cognition and communication in virtual environments are necessary. Simply providing the technical infrastructure doesn't automatically guarantee successful collaboration. Therefore, the analysis of key factors for successful collaboration in virtual environments is an important field of research in the context of the working world of the future. Linking the different fields of this research is a core point for its success. Thus looking for instance at the current media use of students can help to predict the steps that still need to be done, if one day collaboration in virtual learning environments is supposed to prepare for Industry 4.0 on a large scale. But are today's students ready for innovative teaching methods? Current studies of digital media usage show a rather passive usership. The majority of students hardly uses media services which require an increased work load by generating content (e.g. wikis or blogs), as a long-term study on media use of students shows [10]. A study with german engineering students $(n=1587)$ focused on the frequency of usage of different kinds of media services. The results show that interactive and collaborative media services are not used very often by the majority of the sample. This conclusion also counts for blogs or tools for collaborative text production such as wikis. In other words: Absorbing content is still more popular than generating it [11]. 
But the same study reveals another important aspect. Although not many students have been in contact with innovative teaching formats such as serious games or virtual courses in real-time; those who have experience with such formats are highly satisfied with it. These results are of high relevance for the development of virtual collaboration spaces, but also for companies who wish to use them. Developers need to know which the crucial features of a virtual environment are that really solve students" problems and are not just "nice to have". Moreover, universities or companies who invest in virtual learning environments aim for some kind of return on invest, which is not likely to come if the VLE isn't used. However, there is still little evidence on the motifs of students and employees for using, or better for not using media services which require active participation. Although today's students all grew up in a digital society, user profiles are highly diverse. But for a successful implementation of virtual learning it is essential to know how age effects, the attitude to and the behavior within VLEs influence users' learning. Hence, providers of virtual collaboration spaces such as universities or companies need deeper insights in actual user preferences of specific target groups. Which level of graphical precision is required to understand complex processes, which level of gamification is preferred or which kinds of narrative scenarios would motivate this user group to deal with the content longer or more often still needs to be answered for the two potential mainareas of application; the student and the working world. Therefore, in order to investigate the described quantitative research in the field of collaboration in virtual environments, a qualitative research design was chosen, which assessed the perspective of potential users as well as providers. These investigations will be explained in more detail in the following chapter.

Experimental Setting For The Analysis Of Collaboration In Virtual Environments

\section{A. Lead User Workshops with future Engineers}

Since today's students are going to be working within Industry 4.0 contexts it is important to integrate them in the research process on VLEs which are supposed to prepare for the corresponding requirements. The approach of user-centered design is well known in the field of software development, but also under the label of open innovation in the case of new product development [12]. Within idea competitions or lead user workshops, the approach has also proven to be helpful in the development of new teaching methods or new formats of virtual learning in context of the Bologna Process [13]. As representatives of future user groups of such innovative learning and working spaces, students are questioned within focus groups. Two workshops with 23 students from Germany and one workshop with 13 participants of a European study program were conducted.

The two major aims of the workshop series were to collect the students' requirements but also their retentions on VLEs. The students were asked the following questions:

- Which scenarios would you like to experience within VLEs?

- Which didactical method would you prefer, e.g. game based learning, free exploration etc.?

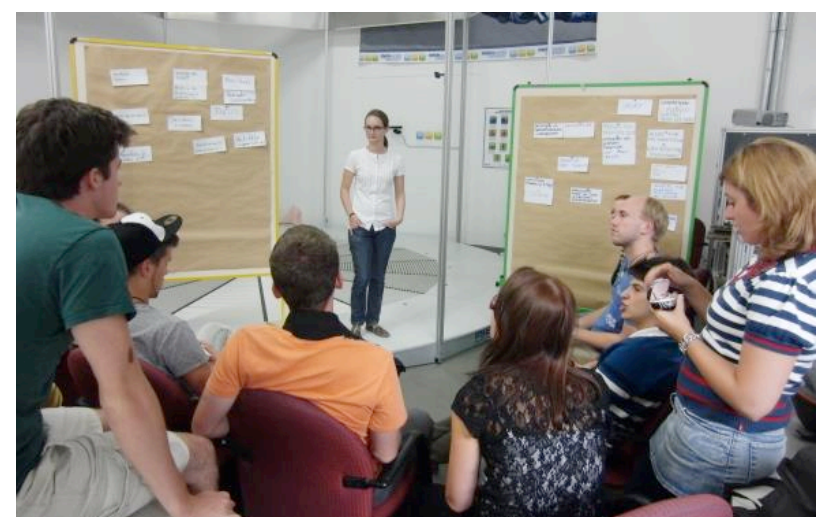

Figure 2. Lead user workshops with students on the topic of virtual learning environments

The students first had to work on the questions in small teams and then presented the results to the whole group. Each idea had to be written down on a prompt card. For a deeper insight into the workshop results, the cards were analyzed with qualitative analysis [14]. The contributions to the two questions were therefore clustered into topics. Afterwards, the quantity of contributions in each category was counted. The topics with the most contributions were considered the ones of greatest interest or greatest concern of the students.

The results of the analysis show that students equally prefer realistic (e.g. factory simulations) and fictional scenarios (e.g. traveling through a factory from the product's perspective). In case of fictional scenarios, the main principle is to exceed the limits of time, space and physics. The students like to be immersed by the virtual environment and to interact with it intuitively and naturally. The possibility to get instant feedback is valued very positive by the students. To combine learning with playing in terms of game based learning is welcomed by the students, but not necessary to enjoy the learning process within the VLE or to consider the VLE useful. The students had no major retentions to VLEs in general, but a few contributions referred to the concern that too many unnecessary features of the VLE could distract from the actual task and the content that should be learned or practiced.

Although surely not being the main contribution to learning success of students, the insights in students' preferences on VLEs delivered important information for the didactical design of future learning environments.

\section{B. Work in Progress: Study on collaboration in virtual environments: The perspective of students,}

In line with the preference of students to be immersed in a VLE, a previous experimental study showed that students who used natural user interfaces for interacting with the virtual environment in individual learning scenarios experienced more immersion than students who solved the task on a laptop. Immersion generally referred to as "diving into the virtual environment" had been operationalized with the constructs of spatial presence and flow. An interaction of experienced flow and errors in task performance revealed the complexity of working in virtual environments: Being immersed by the environment unfortunately can also mean that one is absorbed more by the exploration of the environment than by solving the given 
task [15]. This finding stands in conflict with the user preferences found in the lead student workshops.

However, the nature of collaboration might help to compensate this problem. Since more people are involved in solving a given problem, more attention can be spent on problem-related details. Moreover, as mentioned in the introduction, the prediction of the working world of the future under the label of Industry 4.0 specifically emphasizes the importance of controlling complex, geographically distributed industrial processes [16]. Collaborating in teams with diverse professional and cultural backgrounds is an important precondition for the success of such processes.

To understand the complex interactions of different human factors in situations of virtual collaboration, a current experimental study focuses on preconditions for successful collaborative problem solving in virtual environments. This study assesses the relationship between personal characteristics, objective hardware characteristics, subjective experiences, objective collaboration behavior and task performance. Their expected relationship is visualized in Figure 3.

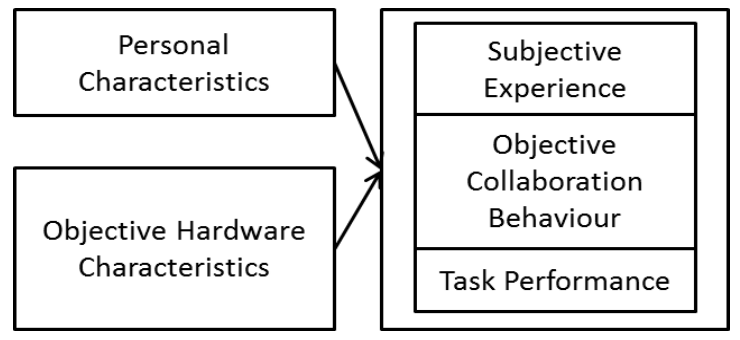

Figure 3. Expected relationship between personal characteristics, hardware characteristics, subjective experiences, objective collaboration behaviour and task performance

The virtual environment is based on the results of the lead user workshops. Therefore the VLE had to be immersive, interactive, give instant feedback on the task performance and have elements of gamification in it. Since in the context of higher education personal and financial resources are mostly small for the development of virtual learning environments, the open-world game Minecraft was chosen as the setting for the learning environment. Minecraft has already been used for teaching and learning settings in the USA and the UK [17] and provides many features which are crucial for virtual collaboration:

- Quick construction of simple learning settings without any programming skills,

- Possibility to build more complex technical environments with the use of blue prints, available mostly for free within the Minecraft community [16],

- Simple and easy to learn modes of interaction without sophisticated gaming skills,

- Possibility to move around freely and to explore the scenario as a user actively.

To link the study to an industry 4.0 scenario, pairs of students are given a task with an engineering background. All participants have to solve the same problem in the same virtual environment, which is to restore electricity in a virtual building. From no perspective within the VLE the whole electrical setting can be viewed completely, which leads to the necessity for the students to actively communicate with each other. The students only know the target state, but not the steps how to get there. The task of restoring electricity within the building can be divided into the following sub-tasks, which have to be encountered by the students without further instructions:

- Get overview of the complete electrical setting of the building,

- $\quad$ Find out, at which spots the electrical circuit is broken,

- Remember the necessary steps to repair the electrical circuit,

- Find the spot within the building from where the success of the problem solving can be controlled.

The process of the collaborative problem solving has to be organized by the students themselves. Before they start as a pair, each student has to run through a tutorial individually. A screenshot of the virtual environment is pictured in Figure 4. To analyze the possible interaction of immersion and task performance, the effect of natural user interfaces is integrated in the research design. The research plan consists of two groups. In both groups, the students work on laptops. Both groups use a simplified keyboard, where all keys except the arrows have been removed. With the arrow keys, the participants control horizontal movement. With a mouse, participants in both groups interact with the VLE. By clicking on the keys of the mouse, they can select different kinds of tools or resources they need to solve the problem. The experimental group fulfills the collaborative task wearing a head mounted display (Oculus Rift, DK 2). The field of view is thereby controlled by natural head movement. The control group controls the field of view by twisting the mouse.

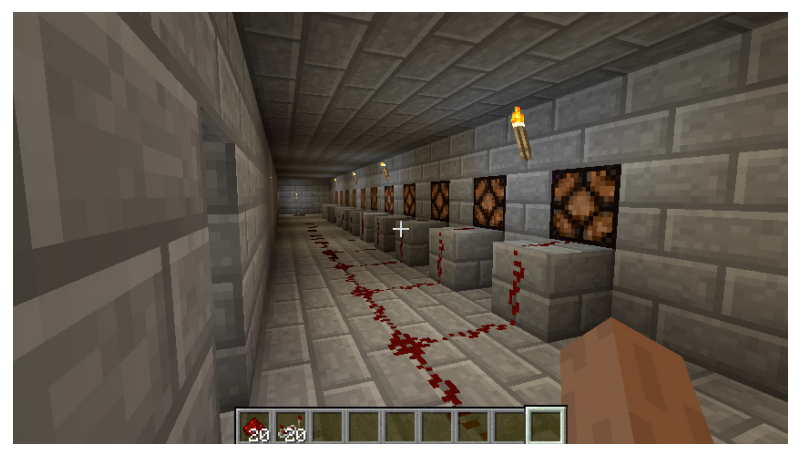

Figure 4. Screenshot of the VLE, implemented in Minecraft

Subjective experiences focus on immersion, operationalized with the constructs of spatial presence and flow. In this study, spatial presence is measured with elements of the MEC Spatial Presence Questionnaire of Vorderer et al. [19]. Flow as the mental state of operation in which a person performing an activity is fully immersed in a feeling of energized focus, full involvement, and enjoyment in the process of the activity, is measured with the shortscale of Rheinberg. According to this instrument, in essence, flow is characterized by complete absorption in what one 
does, as well as the feeling of smooth and automatic running of all task-relevant thoughts [20].

Additionally to the questionnaire, the participants of the study are being interviewed about their experiences. Within the interviews, the experiences are linked with personal characteristics of the participants, e.g. their gaming experience. The subjects are also asked about the experienced quality of the collaboration itself, more precisely their strategies of problem solving, communication and task management. Since diffusion of responsibility within teams has proven to be an inhibiting factor for the success of group work [21] this aspect is also part of the interview. Video camera, screen casts and spatial tracking systems are capturing the behavior of the users. The task performance is measured in time needed for solving the problem.

A total of 8 students between 24 and 34 years $(M=26$; $S D=3.28 ; n=5$ female) volunteered to take part in the pre-study. First screenings of the video material and the screen casts indicate a connection of problem-related speech-acts and task performance. Students, who explicitly verbalize what they do and what they think the other one should do, get quickly to the point when they identify the necessary sub-tasks. For some students, especially those using the oculus rift, the tendency to "chit-chat" about the virtual environment from a meta-perspective and about its immersive effects was noted. For the analysis of the interviews it will be necessary to link this fact to the corresponding task performance. On the one hand, a strong interest in such "meta-information" can mean a positive effect regarding motivational aspects, but on the other hand it can mean some sort of distraction from the actual problem-solving task, as it was indicated in previous studies on learning in virtual environments [15].

Comparing subjective experiences of the quality of collaboration with the actual task performance of the subjects will be another important aspect of the data analysis. However, corresponding conclusions will always have their limitations, since one of the greatest advantages of virtual learning environments is that people can use them at their own preferred speed.

\section{Work in Progress: Study on collaboration and learning in virtual environments: The perspective of professional trainers,}

With the advent of Industry 4.0 and due to the increasing globalization, new forms of learning, and collaboration become more important than ever. In fact, current developments regarding mixed reality devices and hence new possibilities to approach (lifelong) learning are quite progressive and of rising interest for universities, employers and private users. In the last sections the students' perspective about learning and collaboration in VLEs received attention. But for ensuring sustainable learning results it is also important to involve those people who provide and develop professional skills and competence and furthermore cover another age group Based on the structure of the previous described study, this research was investigating the trainers' perspective on mixedreality learning. A total of ten trainers aged between 24 and 60 years $(M=40,7 ; S D=13,2 ; n=2$ female) from different areas in Germany took part in this study. Upon arrival every participants signed the informed consent and was instructed about the experiment and its design. During the experiment participants' spatial behavior within Mine- craft, their answers to questionnaires and from the video analysis, recorded with a screen capture tool were assessed. Additionally to these data, the subsequent interview with the participants gave complementarily insight. To link the results to the study done before and the requirements of Industry 4.0, the participants got a task with an engineering background (see section B). All participants had to solve the same problem in the same virtual environment by wearing a head mounted display (Oculus Rift, DK 2).

The experiment requested communication and collaboration between the trainer and the other person, but in another manner than the previous study did. To get insight into the teachers' perspective of learning in this kind of VLE every participant pursued two roles during the experiment: first the trainee and then the trainer role.

In the first part of the experiment (the trainee-part), the participant was instructed by the research director to restore the electricity in a virtual building. The task per se is stated in section B in more detail. In the second part, a similar problem was stated, but this time the participant had to teach another person who did not know how to solve the stated problem. So the participant had to instruct the other person about how to handle the simplified keyboard and the mouse, make the student comfortable with the VLE and explain the problem without anticipating the problem solving process. During the experiment both screens (participants and scientific staff) were recorded for assessing their behavior in the virtual world.

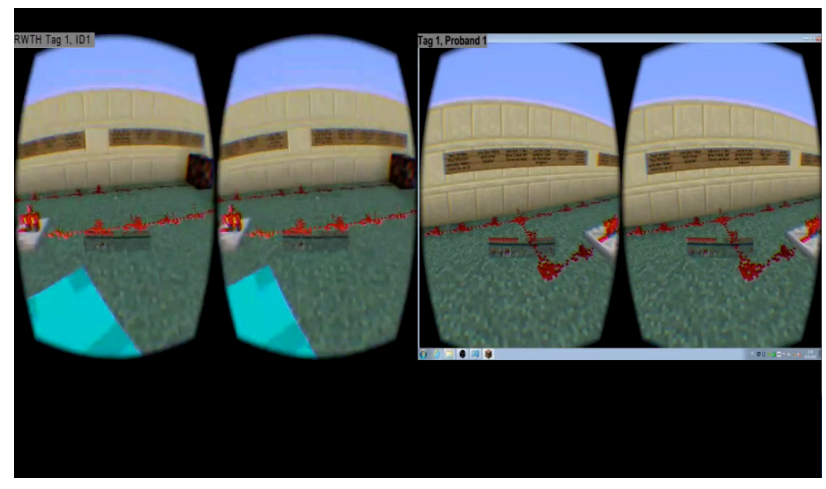

Figure 5. Screenshot of the VLE, implemented in Minecraft, left side: trainers view, right side: trainees view

The screening of the gathered video data indicates that the online gaming experience and the age of participants were shown to have impact on participants' spatial coordination in the virtual world at least in the beginning. Older participants and those who had no gaming experience showed slight difficulties with the hand-cursorcoordination. But these initial difficulties diminished after around the first minute. All participants listened carefully to the instruction they got as trainee and mastered their role as trainer, where they had to transfer the things they just learned and explain a similar problem to another participant. It was shown that participants who documented their course of action out loud as trainee and gave clear instructions as trainer performed quite more efficient. After their participation, the subjects were asked to anonymously evaluate their previous learning experience in the VLE and answer quantitative questions regarding the experience of the new technology they just had. The participants' overall conclusion was very positive: It looks 
like the barriers for the affected teachers are between nonexistent and low regarding utilization of virtual worlds for teaching, whereas the benefit of VLE was considered as huge. The additional expert interview gave more insight into the data and the trainer's view.

The training was rated as very adaptive and the participants' pronounced the feeling of immersion into the virtual world. The trainers' particularly mentioned the possibility to represent and adapt specific learning content and their feeling of deep and conscious learning as well as the fast familiarization with the virtual world and navigation within it.

As possible fields of application the trainer called among other things fields like emergency services, schooling of security staff and training of techniques which are too hazardous for training in field as well as normal kinds of everyday school for education and development. As a particular advantage of learning in virtual worlds, the resource efficiency and flexibility as well as the targeting of many senses at one and the consequential deep learning were emphasized. To the question of potential difficulties with virtual worlds for trainees and trainers, initial problems with the usage and the acceptance of technology were mentioned. But the benefits exceeded the possible adverse effects many times over. When asked about further suggestions, the trainers emphasized the importance of VLE for learning, economy and companies as well as the interlocking of economy and research within this field.

\section{CONCLUSION}

The qualitative research on collaboration in virtual environments gives deeper insights into the relationship of personal preferences for VLEs, subjective experiences within them and actual task performance. To focus on virtual collaboration delivers important research results for universities and companies who wish to use virtual environments in the future with the vision of Industry 4.0 in mind. The preliminary results of the video analysis of the pre-study with students indicate the importance of communication within virtual environments. If performance within VLEs is to be enhanced even from today's point of view, to train staff in virtual communication skills would be a promising point to start.

The approach of user-centered design thereby helped to get deeper insights into specific design preferences of VLEs from a user group, who grew up in a digitalized society. However, the preferences can also be due to age instead of cohort.

The third work in progress part allows, next to students' perspective, first insight into the perspective of professional trainers. Again importance of communication within virtual environments' was indicated. Next to this finding gaming experience and the age of participants were shown to affect participants' spatial coordination in the VLE, but difficulties were reduced by more thorough introduction phases. Initial results of trainers' evaluation of learning and collaboration within VLEs as well as their answers to the interview are auspicious-and emphasize the potential of this field of research. Especially in the light of demographic change and aging populations in Europe, it will be crucial to continue the kind of studies that have been presented in this paper. For the effective virtual collaboration within diverse teams, another research area covers collaboration of pairs with different skill levels: of novices and experts, of young and old co-workers or of IT-close vs. IT-distant people. Who can work best with whom, and in what kind of virtual environment will be an important aspect for effective human resources planning in companies.

Should research one day prove actual financial benefits of virtual collaboration, e.g. by reducing travel costs, this way of working will soon become established. Companies who know how to collaborate in virtual environments efficiently will have a strong competitive advantage compared to those who don't. Continuing this kind of research therefore is an important contribution towards a globalized, connected and digitalized working world in terms of industry 4.0 .

\section{REFERENCES}

[1] B. Haerdle, „Die Digitalisierung der Lehre“. Wirtschaft und Wissenschaft, vol. 4, p. 12, 2013.

[2] Moodle: Moodle Statistics. [Online]. Available:https://moodle.net/stats/ . Accessed on March 12, 2015.

[3] L. Johnson et al., NMC Horizon Report: 2014 Higher Education Edition. Austin: The New Media Consortium, 2014.

[4] H. M. Niegemann et al., Kompendium multimediales Lernen. Berlin Heidelberg: Springer, pp. 338 f, 2008.

[5] Federal Ministry of Education and Research: Industrie 4.0 [Online]. Available: http://www.pt-it.pt-dlr.d e/de/3069.php , Accessed on March 11, 2015.

[6] C. Bösenberg and B. Küppers, "Im Mittelpunkt steht der Mitarbeiter". Freiburg: Haufe-Lexware, 2011.

[7] C. Terkowsky, D. May, T. Haertel and C. Pleul .’Experiential remote lab learning with e-portfolios: Integrating tele-operated experiments into environments for reflective learning".15th International Conference on Interactive Collaborative Learning (ICL), pp. 1-7, September 2012.

[8] D. Ewert et al., "Intensifying learner's experience by incorporating the virtual theatre into engineering education". In Proceedings of the IEEE EDUCON Conference, Berlin, pp. 13-15, 2013.

[9] Computerbild: Virtuelle 3D Welten sind auf dem Vormarsch. [Online]. Available: http://www.tricat.net/site/assets/files/1595/2015 $01 \quad 15$ artikel 3d lern- und arbeitswelten computerwoche.pdf . Accessed on June $17,2015$.

[10] E. Dahlstrom, J.D. Walker, and C. Dziuban "ECAR Study of Undergraduate Students and Information Technology". EDUCAUSE Center for Analysis and Research. Louisville, 2013.[Online]. Available: http://www.educause.edu/ecar . Accessed on March 12, 2015.

[11] G. Gidion, G and M. Grosch, ,Welche Medien nutzen die Studierenden tatsächlich? Ergebnisse einer Umfrage zu den Mediennutzungsgewohnheiten von Studierenden“. In: Forschung \& Lehre. Deutscher Hochschulverband (Hrsg.), June 2012. [Online]. Available: http://www.forschung-undlehre.de/wordpress/Archiv/2012/ful_06-2012.pdf . Accessed on March 12, 2015.

[12] E. von Hippel, "Democratizing Innovation". Cambridge: MIT Press, 2005.

[13] J. Koch et al, „Open Innovation - Kunden als Partner Wie Hochschulen von Unternehmen lernen können“, in Wissenschaftsmanagement, vol. 17, Bonn: Lemmens, pp. 31-35, 2011.

[14] J. Gläser and G. Laudel „Experteninterviews und qualitative Inhaltsanalyse“. Wiesbaden: VS Verlag für Sozialwissenschaften, 2010.

[15] K. Schuster et al. "Diving in? How Users Experience Virtual Environments Using the Virtual Theatre", in Proceedings of the 3rd International Conference on Design, User Experience, and Usability, Crete, June 2014, pp. 636-646.

[16] Federal Ministry of Education and Research: Industrie 4.0. [Online]. Available: http://www.pt-it.pt-dlr.de/de/3069.php Accessed on March 12, 2015. 
[17] The Minecraft Teacher. Online: http://minecraftteacher.tumblr.com/ [accessed on 12.03.2015].

[18] Elterpro: Realistisches Atomkraftwerk mit Kontrollzentrale. Video on Youtube [Online]. Available: https://www.youtube.com/watch?v=172VcTI4D88. Accessed on March 12, 2015.

[19] P. Vorderer et al., "MEC Spatial Presence Questionnaire (MECSPQ): Short Documentation and Instructions for Application". Report to the European Community, Project Presence: MEC (IST2001-37661), 2004 [Online]. Available: http://www.ijk.hmthannover.de/presence. Accessed on Oct. 14, 2012.

[20] F. Rheinberg, R. Vollmeyer, and S. Engeser, „Die Erfassung des Flow-Erlebens“. In: Stiensmeier-Pelster, J.; Rheinberg, F. (Hrsg.): Diagnostik von Motivation und Selbstkonzept. Test und Trends. Göttingen: Hogrefe, pp. 261 - 279, 2013.

[21] H. M. Niegemann et al. Kompendium multimediales Lernen. Berlin Heidelberg: Springer, pp. 338 f, 2008.

\section{AUTHORS}

Dr. Katharina Schuster is researcher and leader of the research group "Didactics in STEM fields" at the Center for Learning and Knowledge Management (ZLW) in the institute cluster IMA/ZLW \& IfU at RWTH Aachen University, Aachen, Germany (e-mail: katharina.schuster@ ima-zlw-ifu.rwth-aachen.de).

Lana Plumanns is researcher in the research group "Economic and Social Cybernetics" at the Assoc. Institute for Management Cybernetics e.V. (IfU) in the institute cluster IMA/ZLW \& IfU at RWTH Aachen University ,Aachen, Germany (e-mail: lana.plumanns@ima-zlwifu.rwth-aachen.de.
Kerstin Groß is researcher in the research group "Didactics in STEM fields" at the Center for Learning and Knowledge Management (ZLW) in the institute cluster IMA/ZLW \& IfU at RWTH Aachen University, Aachen, Germany (e-mail: kerstin.gross@ima-zlw-ifu.rwthaachen.de).

Dr. Rene Vossen is managing director of the Assoc. Institute for Management Cybernetics e.V. (IfU) in the institute cluster IMA/ZLW \& IfU at RWTH Aachen University, Aachen, Germany (e-mail: rene.vossen@ima-zlwifu.rwth-aachen.de).

Prof. Anja Richert is managing director of the Center for Learning and Knowledge Management (ZLW) in the institute cluster IMA/ZLW \& IfU at RWTH Aachen University, Aachen, Germany (e-mail: anja.richert@ima-zlwifu.rwth-aachen.de).

Prof. Sabina Jeschke is director of the institute cluster IMA/ZLW \& IfU and vice dean of the department of mechanical engineering at RWTH Aachen University, Aachen, Germany (e-mail: sabina.jeschke@ima-zlwifu.rwth-aachen.de).

This work was supported by the Federal Ministry of Education and Research of Germany within the project "Excellent teaching and learning in engineering sciences (ELLI)". It is an extended and modified version of a paper presented at the the International Conference on E-learning in the Workplace 2015 (ICELW'15), held in June 2015, at Columbia University in New York, NY, USA. Submitted 19th March 2015. Published as resubmitted by the authors 30 November 2015 . 